\title{
MONITORAMENTO DA FERTILIDADE DO SOLO SUBMETIDO À EROSÃO HÍDRICA EM ÁREA CULTIVADA COM EUCALYPTUS SP. EM SÃO JOÃO EVANGELISTA - MG
}

\author{
Dênniel Trajinelli Coelho Pinheiro ${ }^{11}$, Claudionor Camilo da Costa ${ }^{2}$,Leandro Lopes Motta ${ }^{1}$, \\ Fernando Coelho Godinho ${ }^{1}$, Jadir Vieira da Silva ${ }^{1}$
}

\section{RESUMO}

Este trabalho teve como objetivo quantificar as perdas de fósforo $(\mathrm{P})$, potássio $(\mathrm{K})$, magnésio $(\mathrm{Mg})$ e cálcio $(\mathrm{Ca})$ no sedimento erodido e comparar as variações da matéria orgânica (MO), potencial hidrogeniônico $(\mathrm{pH})$ e capacidade de troca catiônica efetiva (CTC) do solo com os sedimentos carreados por erosão hídrica em cultura de eucalipto sob chuva natural. Para as coletas das amostras de solo erodido foi instalado um tratamento pelo método de parcela padrão com dimensões de 12 x $24 \mathrm{~m}$ com declividade de $42 \%$ no sentido longitudinal. As coletas foram feitas no período compreendido entre janeiro a abril de 2009 após cada evento de chuva erosiva assim classificada, cujos registros foram maiores que $10 \mathrm{~mm} \mathrm{~h}^{-1}$. As amostras de solo foram retiradas dos tanques de coletas e encaminhadas ao laboratório de solos do Instituto Federal de Minas Gerais, onde os sedimentos foram secados e analisados quimicamente. As perdas totais de nutrientes foram de $11,42 \mathrm{~kg} \mathrm{ha}^{-1}$ representadas por $63 \%$ de $\mathrm{Ca}, 18 \%$ de $\mathrm{Mg}, 13 \%$ de $\mathrm{Ke} 6 \%$ de P. O pH e CTC apresentaram um aumento das suas concentrações nos sedimentos erodidos e a MO não apresentou variações.

Palavras-chave: Perda de nutrientes, Erosão Hídrica, Fertilidade do solo

\section{Fertility monitoring of the soil submitted to water erosion in cultivated plots with Eucalyptus sp in São João Evangelista - MG}

\section{ABSTRACT}

This study aimed to quantify the losses of phosphorus $(\mathrm{P})$, potassium $(\mathrm{K})$, magnesium $(\mathrm{Mg})$ and calcium $(\mathrm{Ca})$ in the sediment and compare variations in organic matter $(\mathrm{OM})$, hydrogen potential $(\mathrm{pH})$ and the ability to cation exchange capacity (CEC) of soil sediments carried lost by erosion in crop plantations under natural rainfall. For the collection of samples of soil eroded was installed by a treatment method with standard portion sizes of $12 \times 24 \mathrm{~m}$ at $42 \%$ of slope in the longitudinal way. Collections were made during the period from January to April of 2009 after each erosive rainfall event as classified, whose record was greater than $10 \mathrm{~mm} \mathrm{~h}^{-1}$, with a maximum intensity above 3.6 MJ. Soil samples were taken from the tanks and sent samples to the laboratory for soils of the Institute Federal of Minas Gerais, where the sediments were dried and analyzed chemically. The total losses of nutrients were of $11.42 \mathrm{~kg} \mathrm{ha}^{-1}$ which had $63 \%$ of $\mathrm{Ca}, \mathrm{Mg} 18 \%, 13 \%$ of $\mathrm{K}$ and $6 \%$ of P. The $\mathrm{pH}$ and CEC showed an increase in their concentrations in sediment eroded and OM did not vary.

Key words: Loss of nutrients, Water erosion, Soil fertility.

\footnotetext{
${ }^{1}$ Tecnólogo em Silvicultura pelo Instituto Federal Minas Gerais- campus São João Evangelista-MG CEP $39705-000$ São João Evangelista-MG.jadirvsilva@yahoo.com.br

2 Professor do Instituto Federal de Minas Gerais Campus São João Evangelista CEP 39705-000 São João Evangelista-MG. claudionor. costa@ifmg.edu.br
} 


\section{INTRODUÇÃO}

A erosão é um processo caracterizado pelo desprendimento e arraste das partículas de um solo juntamente com os nutrientes e matéria orgânica (MO) adsorvidos aos sedimentos e carreados pela erosão hídrica, como consequência do impacto das gotas da chuva e $o$ subsequente transporte das partículas por fluxo superficial (Cassol e Reichert, 2002).

Segundo Oliveira (2007), a erosão é a principal fonte de desgaste progressivo do solo e obstáculo ao aumento sustentável de produtividade, provocando grandes perdas de terras agricultáveis. Anualmente, as perdas de solo em pastagens e lavouras no Brasil superam a marca de 822 toneladas (t), apresentando financeiramente prejuízo da ordem de $\mathrm{R} \$ 7,33$ bilhões em reposição de corretivos e adubos químicos a estas áreas e mais $\mathrm{R} \$ 3,29$ bi com manutenção de estradas e tratamentos de água.

A declividade do terreno é um fator que influencia fortemente as perdas de água e solo por erosão hídrica, pois, à medida que ela aumenta, o volume e a velocidade da enxurrada serão maiores, diminuindo a infiltração de água no solo. Com isso, eleva-se a capacidade de transporte das partículas de solo pela enxurrada, bem como a própria capacidade dessa em desagregar o solo, principalmente quando concentrada em sulcos direcionados no sentido da pendente do terreno.

A cobertura do solo, proporcionada pelos resíduos culturais deixados na superfície, tem ação direta e efetiva na redução da erosão hídrica, pois promove a dissipação da energia cinética das gotas da chuva, diminuindo a desagregação das partículas e do selamento superficial do solo, aumentando a infiltração de água. Atua ainda na redução do volume e da velocidade do escoamento superficial e, consequentemente, no potencial erosivo da enxurrada (Cogo et al., 1984).

Pires (2004) estudando um Latossolo Vermelho-Amarelo, determinou a tolerância admissível de perdas de solo por erosão hídrica na faixa de $7,17 \mathrm{tha}^{-1}$ ano $^{-1}$

\section{Relação entre as propriedades físicas e a erosão hídrica do solo}

Segundo Oliveira (2007), as propriedades físicas do solo influenciam diretamente no processo erosivo. Dentre elas, aquelas que afetam a taxa de infiltração e permeabilidade e aquelas que influenciam a resistência do solo às forças de dispersão, salpico e transporte, são consideradas de maior importância nos estudos de erosão do solo. No sentido, Chaves et al. (1993), colocam que as propriedades físicas do solo regulam a infiltração e a movimentação da água ao longo do perfil, influenciando no escoamento superficial e na resistência ao impacto da gota da chuva.

Bertol et al. (2004a) trabalhando com Cabimbissolo Húmico, verificou que as perdas de nutrientes foram menores nos preparos conservacionistas do que em preparos convencionais.

\section{Efeito da erosão hídrica}

O principal impacto da erosão hídrica do solo é a constante redução da fertilidade do mesmo (Bahia et al., 1992).

Segundo Bertol et al. (2004a), a erosão hídrica do solo ocasiona perda de nutrientes, além de contaminar os mananciais e outras áreas fora do local de origem da erosão, diminuindo a produtividade agrícola pelo empobrecimento do solo. A contaminação dos mananciais é ocasionada pelaenxurradasuperficial,quetransportasedimentos com nutrientes (solúveis e adsorvidos) em altas concentrações, podendo provocar a eutrofização das águas onde se depositam (Guandagnin, 2005).

Cavichiolo (2005) destaca o problema ambiental causado pelo processo de erosão hídrica, uma vez que, os nutrientes depositados nos corpos de água, podem resultar na eutrofização favorecendo o crescimento da microbiota aquática, a mortalidade de peixes e elevando a turbidez dos 
mananciais. Pode ainda comprometer o uso da água para fins doméstico e industrial, em função do aumento da dureza da água.

Outro efeito nocivo da degradação de um solo é a redução de sua capacidade de retenção e armazenamento de água, indispensável ao desenvolvimento da vegetação. Se o solo não retem água suficiente, a produção das culturas é comprometida. Os processos conservacionistas objetivam manter o solo e a água no terreno, com técnicas que visem aumentar a infiltração e reduzir o escoamento superficial (Corrêa, 2009).

\section{Perda de nutriente por erosão hídrica}

As concentrações de nutrientes presentes no material erodido são relacionadas com as concentrações destes na camada superficial do solo (Oliveira, 2007), as quais são influenciadas pelas adubações, pela cobertura e manejo do solo (Bertol et al., 2004a). Já Bertol et al. (2004b) afirmam que a perda total de nutrientes nos sedimentos carreados do solo em decorrência da erosão hídrica depende dos totais de água e sedimentos transportados, além da concentração dos referidos nutrientes nos sedimentos.

Silva et al. (2005) caracterizaram a seletividade de arraste de material no processo de erosão hídrica, que transporta principalmente as partículas mais finas, as frações mais reativas do solo e, consequentemente, com maior capacidade de carrear nutrientes e carbono orgânico.

Olivera (2007) percebeu que na água da enxurrada não foram registradas perdas de fósforo devido aos baixos valores desse elemento no solo, pelo fato do mesmo estar adsorvido aos colóides do solo. O maior transporte se deu nas frações de argila e silte implicando em maiores perdas nos sedimentos carreados pela enxurrada. Como aquele elemento químico é fortemente adsorvido pelas argilas, uma maior proporção é transportado na forma adsorvida juntamente com as partículas do solo, fato que pode explicar a não ocorrência do elemento em suspensão na água da enxurrada.

Silva et al. (2005) afirmam que as maiores perdas de $\mathrm{P}$ acompanham as perdas de carbono orgânico (CO) e as maiores taxas de perdas de solo, o que se deve em parte ao $\mathrm{P}$ orgânico e pelo fato desse nutriente ser preferencialmente perdido por erosão e transportado adsorvido à fração coloidal mineral.

Para o K, as maiores perdas foram registradas na água da enxurrada. Normalmente as perdas deste elemento químico em solução são maiores que as encontradas no sedimento, em função da maior solubilidade do mesmo. A perda desse nutriente no sedimento carreado pela enxurrada foi relativamente baixa quando comparada as suas perdas na água escoada (Oliveira, 2007).

As perdas de $\mathrm{P}$ e $\mathrm{K}$ nos sedimentos da enxurrada foram baixas nos tratamentos conservacionistas, apesardas altas concentrações destes nos sedimentos, que está associada à aplicação de adubos na superfície, aumentando os teores deles na camada superficial do solo. Assim as baixas quantidades de $\mathrm{P}$ e $\mathrm{K}$ perdido neste sistema foram influenciadas, pelas baixas perdas de solo ocorridas. No caso de preparos convencionais, a alta perda $\mathrm{P}$ e $\mathrm{K}$ nos sedimentos é explicada pela alta perda de solo, devido o seu revolvimento. As concentrações desses elementos nos sedimentos foram baixas, devido à incorporação desses nutrientes ao solo, (Bertol et al., 2004a).

As maiores concentrações de $\mathrm{Ca}$ e $\mathrm{Mg}$ presentes nos sedimentos da enxurrada na semeadura direta podem ser explicadas pelas maiores concentrações desses elementos na superfície do solo, decorrentes da forma superficial de aplicação do calcário, (Bertol et al., 2004b). Os mesmos autores apontam as perdas de $\mathrm{Ca}$ e $\mathrm{Mg}$ sendo influenciadas pelas perdas de solo e pelas concentrações desses elementos nos sedimentos em virtude da calagem e por serem elementos poucos sujeitos a lixiviação e fortemente adsorvidos ao solo. As perdas de $\mathrm{Ca}$ e $\mathrm{Mg}$ foram, respectivamente, 58 e 67 vezes maiores no sistema de preparo convencional do que na semeadura direta. 
Conforme Silva et al. (2005) e Wichert (2005), as perdas de nutrientes e matéria orgânica acompanham as perdas de solo, sendo encontrado nos sedimentos de erosão a seguinte tendência, em ordem decrescente: $\mathrm{Ca}>\mathrm{K}>\mathrm{Mg}>\mathrm{P}$, não concordando com Oliveira (2007) que apresenta na seguinte ordem: $\mathrm{Ca}>\mathrm{Mg}>\mathrm{K}>\mathrm{P}$.

Wichert (2005) revisando a literatura pertinente mostrou em um solo podzolizado que o sedimento transportado pela erosão apresentava duas vezes mais MO; 2,8 mais $\mathrm{P}$; 2,3 mais $\mathrm{Ke}$ 1,9 mais $\mathrm{Ca}$ do que no solo original. O mesmo autor, para um estudo de plantio de E. grandis no primeiro ano em areia quartzoza, constatou perdas de nutrientes pelo escoamento superficial, sendo os valores, Ca 3,2 a 4,1; K 0,6 a 1,$9 ; \mathrm{Mg} 0,2$ a $0,3 \mathrm{~kg} \mathrm{ha}^{-1}$. Observou ainda que o solo erodido é ligeiramente mais fértil que o solo original, CTC média do solo original de 106 e do solo erodido de 120 mmolc kg-1, mas com o mesmo teor de matéria orgânica. Este enriquecimento se deveu ao fato da erosão ocorrer na camada superficial do solo.

Trabalhando com remoção de camadas de solo, Veiga et al. (1993) verificaram uma crescente degradação das características que avaliaram a fertilidade do solo, como a diminuição nos teores de $\mathrm{MO}, \mathrm{P}, \mathrm{K}, \mathrm{Ca}$ e $\mathrm{Mg}$ trocável e o aumento nos teores de Al trocável, refletindo no desenvolvimento e rendimento das plantas. Os autores observaram ainda que, mesmo com a aplicação de calcário ou a combinação de calcário e NPK, não foi possível recuperar a produtividade para os níveis dos tratamentos sem remoção de camadas.

Tendo em vista os aspectos abordados anteriormente, estetrabalhoobjetivou quantificar as perdas de fósforo $(\mathrm{P})$, potássio $(\mathrm{K})$, magnésio $(\mathrm{Mg})$ e cálcio $(\mathrm{Ca})$ por meio do sedimento erodido e comparar as variações dos teores da $\mathrm{MO}, \mathrm{pH}$ e capacidade de troca catiônica efetiva (CTCe) do solo com os sedimentos carreados por erosão hídrica em cultura de eucalipto sob chuva natural em um Latossolo VermelhoAmarelo Distrófico.

\section{MATERIAL E MÉTODOS}

$\mathrm{O}$ experimento foi instalado no Instituto Federal de Educação, Ciência e Tecnologia de Minas Gerais - Campus de São João Evangelista (IFMG - Campus SJE), localizado na bacia hidrográfica do Rio Doce (sub bacia do Suaçuí Grande), região Centro Nordeste do Estado de Minas Gerais. O clima é classificado, de acordo com Köppen, como Cwa (inverno seco e verão chuvoso), sendo predominantemente nesta região o clima do tipo tropical, apresentando uma temperatura média mínima de $22^{\circ} \mathrm{C}$ e média máxima de $27^{\circ} \mathrm{C}$ por ano, precipitação média anual de $1.180 \mathrm{~mm}$ e a altitude média de $680 \mathrm{~m}$ (Portalsjevanjelista, 2009).

A área onde o experimento foi instalado possui coordenadas $18^{\circ} 32^{\prime} 56^{\prime}$ " latitude Sul e $42^{\circ} 45^{\prime} 42^{\prime}$ longitude Oeste e altitude do local é $753 \mathrm{~m}$. O local atualmente cultivado com eucalipto (com 04 anos de idade) foi ocupado com pastagem há alguns anos, a qual foi se degradando paulatinamente e no ano de 2005 foi implantado o cultivo de eucalipto. Esse é o primeiro cultivo desta espécie vegetal no histórico desta área. Utilizouse o clone híbrido de Eucalyptus urograndis, com o espaçamento de 3,0 × 3,0 m (mil cento e onze árvores por hectare), em covas feitas manualmente com enxadão (cultivo mínimo), com dimensões de $0,30 \times 0,30 \times 0,30 \mathrm{~m}$. Na adubação de plantio, utilizaram $90 \mathrm{~g}$ de NPK (respectivamente, nitrogênio, fósforo e potássio) na formulação 6-30-6, $320 \mathrm{~g}$ de fosfato reativo e $1 \mathrm{~kg}$ de calcário por cova, e $270 \mathrm{~g}$ de $\mathrm{KCl}$ (cloreto de potássio) por planta, aplicados em cobertura. Depois do plantio foram feitas duas capinas manuais, no ano de 2006. Estes dados foram fornecidos pelo Setor de Agricultura do IFMG - Campus SJE.

O solo da área experimental foi classificado como Latossolo Vermelho-Amarelo Distrófico, com o horizonte A proeminente e textura arenosa.

O local escolhido para a instalação da parcela experimental na floresta de eucalipto apresentou declividade média representativa do 
relevo predominante da localidade estudada. A declividade medida com nível óptico foi de $42 \%$.

O tratamento utilizado foi constituído pelo seguinte sistema de cultivo: Clone Híbrido de Eucaliptus urophylla $x$ Eucaliptus grandis com 36 meses de idade.

Foi instalada no campo a parcela-padrão (Figura 1), com dimensão de 12×24 m no interior da floresta de Eucalipto, onde a maior dimensão ficou no sentido do declive, totalizando em 288 $\mathrm{m}^{2}$. Essa parcela foi contornada com chapas galvanizadas com $0,40 \mathrm{~m}$ de altura, sendo $0,20 \mathrm{~m}$ na superfície do solo e enterrados os outros $0,20 \mathrm{~m}$ restantes. A parte inferior da parcela continha calhas coletoras, das quais saía um tubo de PVC de três polegadas (aproximadamente $75 \mathrm{~mm}$ ) para conduzir a enxurrada até o tanque de sedimentação com capacidade de $500 \mathrm{~L}$ e outro tubo que ligava o primeiro tanque a um segundo tanque coletor de água e sedimentos com capacidade de $250 \mathrm{~L}$. Entre o tanque de sedimentação e o tanque coletor havia um sistema divisor do tipo Geib com 15 janelas para que, depois do enchimento do tanque de sedimentação, apenas 1/15 da enxurrada fosse conduzida para o coletor.

Foram coletadas aleatoriamente duas amostras compostas de solo, com o auxílio de uma sonda, na profundidade de $0-20 \mathrm{~cm}$ no início e no final das avaliações, na área experimental, para se saber os teores de $\mathrm{P}, \mathrm{K}, \mathrm{Mg}, \mathrm{Ca}, \mathrm{MO}, \mathrm{pH}$ e CTCe. Tais amostras foram usadas em comparação com as demais que foram coletadas após cada evento de chuva erosiva assim classificada, cujos registros foram maiores que $10 \mathrm{~mm} \mathrm{~h}^{-1}$ conforme Pires et al. (2006), no período compreendido entre janeiro e abril de 2009. As coletas dos sedimentos foram realizadas no tanque de sedimentação de $500 \mathrm{~L}$ (figura 2), com o auxílio de uma pá. As amostras foram acondicionadas em sacos plásticos e encaminhadas ao laboratório de solos do IFMG Campus SJE, onde as mesmas foram submetidas à analise química. Este estudo em parcela padrão não apresenta repetição de tratamento.

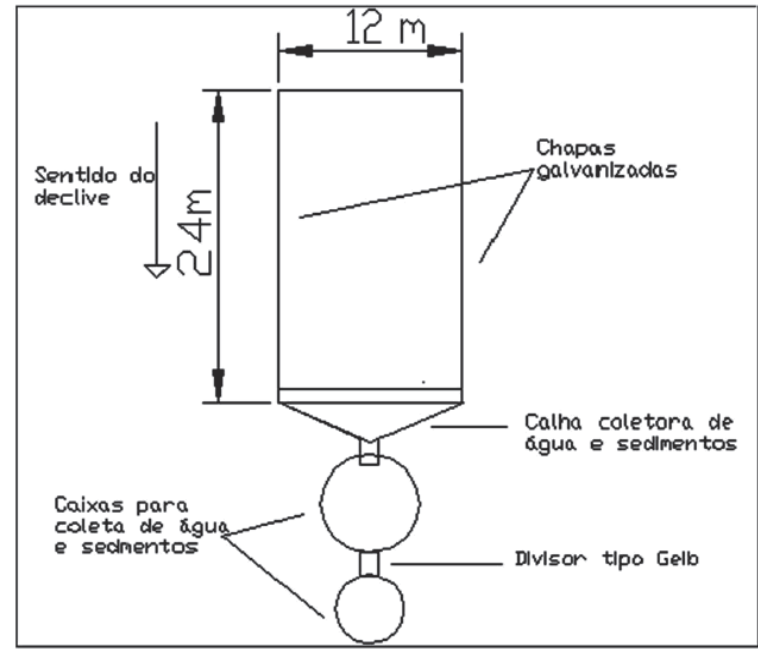

FIGURA 1 - Desenho esquemático da parcela padrão de coleta de sedimentos.

Ilustração: os autores.

Fonte: Os autores.

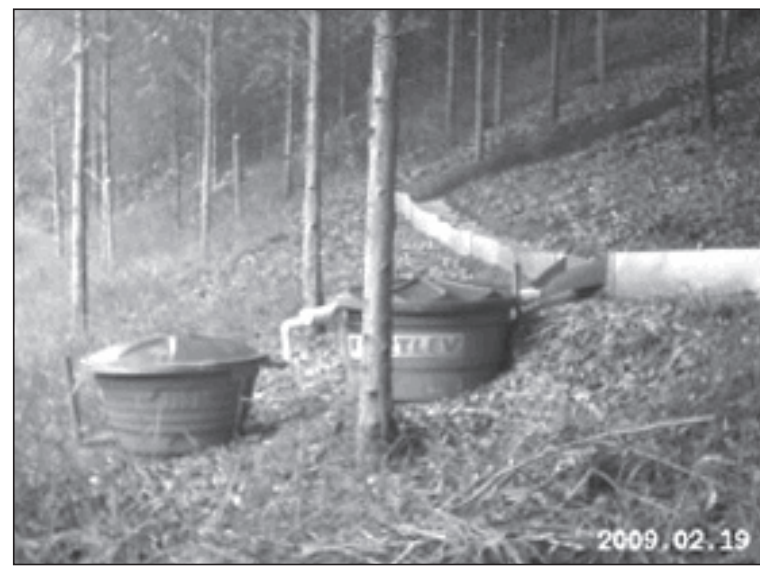

FIGURA 2 - Tanques de coletas de sedimentos, com vista parcial da parcela padrão.

Fonte: Os autores.

Para monitoramento das precipitações, foi instalado nas proximidades da parcela um pluviômetro de plástico .

Para melhor interpretação e discussão dos resultados analíticos de fertilidade do solo foram feitas conversões das unidades segundo (Lopes \& Guilherme 2004). 


\section{RESULTADOS E DISCUSSÃO}

Os nutrientes apresentaram altas concentrações nos sedimentos (tabela 1) e baixas perdas totais de solo, quando comparadas com a tolerância admissível para este tipo de solo (Pires, 2004), na ordem de 259,9 Kg ha $^{-1}$ (Silva et al., 2009), que desenvolveram um trabalho concomitante a este . A perda total de nutrientes foi de $11,42 \mathrm{~kg} \mathrm{ha}^{-1}$, sendo obtida pela soma da perda total de cada nutriente. Utilizou-se o cultivo mínimo, em que, não houve revolvimento do solo e a boa cobertura do eucalipto sobre o solo certamente influenciaram as maiores concentrações desses nutrientes na superfície do terreno e também pela baixa perda de solo e, conseqüentemente, de nutrientes, corroborando Bertol et al. (2004a).

TABELA 1. Análise química do solo inicial (1 SOL) e final (2 SOL) e de sedimentos (1 a 7 SED), após cada evento de chuva erosiva, durante o período de estudos.Fonte: Os autores.

\begin{tabular}{|c|c|c|c|c|c|c|c|}
\hline \multirow{2}{*}{\multicolumn{2}{|c|}{$\begin{array}{c}\mathrm{pH} \\
\left(\mathrm{H}_{2} \mathrm{O}\right)\end{array}$}} & $\mathrm{P}$ & K & $2+$ & $\mathrm{Ma}^{2+}$ & \multirow{2}{*}{$\begin{array}{c}\mathrm{MO} \\
\left(\mathrm{dag} \mathrm{kg}^{-1}\right)\end{array}$} & \multirow{2}{*}{$\begin{array}{l}\text { CTCe } \\
\left(\mathrm{cmol}_{\mathrm{c}}\right. \\
\left.\mathrm{dm}^{-3}\right)^{\circ}\end{array}$} \\
\hline & & \multicolumn{4}{|c|}{$\left(\mathrm{mg} \mathrm{dm} \mathrm{d}^{-3}\right)$} & & \\
\hline & 4,42 & 0,2 & 20,0 & & & & 0,40 \\
\hline & 4,50 &, 2 & 2,0 & & & & 0,86 \\
\hline & 4,8 & & & & & & 0,76 \\
\hline & 5,02 & 10,7 & 15,0 & & & & 0,54 \\
\hline & 5,0 & & 1 & & & &, 65 \\
\hline & 5,08 & & 19,0 & & & & 0,65 \\
\hline & 5,6 & 50,9 & 27,0 & & & & 1,72 \\
\hline & 5,8 & & 31 & & & & 1,58 \\
\hline 7 SED & 6,16 & 3,9 & 52,0 & 240,47 & 72,94 & 2,41 & 1,93 \\
\hline
\end{tabular}

Os sedimentos transportados pela erosão apresentaram as seguintes taxas de enriquecimento: 1,76 vezes mais $P ; 1,27$ mais $\mathrm{K}$; 4,48 mais $\mathrm{Ca}$ e 3,14 mais $\mathrm{Mg}$ do que no solo original. Estes resultados foram obtidos pela fórmula:

$\mathbf{T E}=\mathbf{N}_{\text {sed }} / \mathbf{N}_{\text {sol }}$
$\mathrm{TE}=$ taxa de enriquecimento;

$\mathrm{N}_{\text {sed }}=$ concentração média do elemento nos sedimentos; e

$\mathrm{N}_{\text {sol }}$ = concentração média do mesmo elemento no solo.

A taxa de enriquecimento indica o quanto à concentração de nutrientes no sedimento foi superior ao solo original.

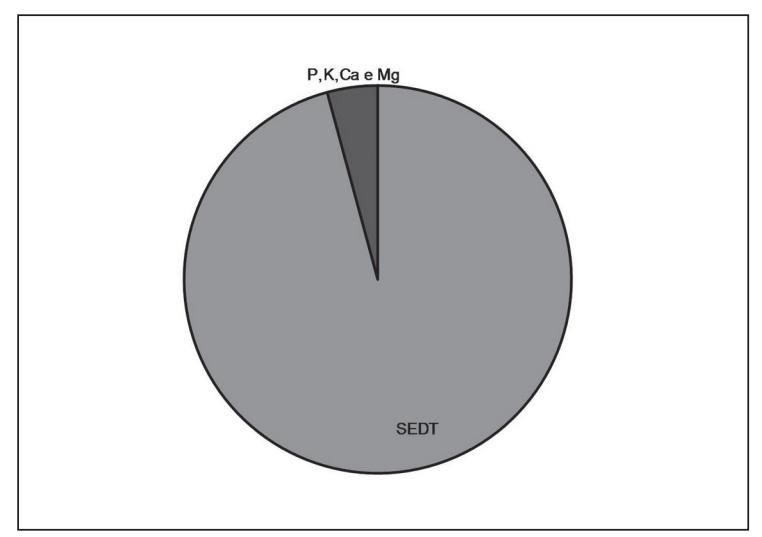

FIGURA 3 - Sedimento total perdido (SEDT) e a fração total correspondente aos nutrientes (P, K, Ca e $\mathrm{Mg}$ ) perdidos, para o tempo de estudo. Fonte: Os autores.

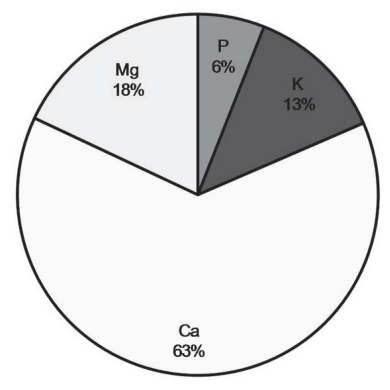

FIGURA 4 - Desfragmentação e porcentagem de cada nutriente perdido, para o tempo de estudo. Fonte: Os autores.

Pode-se observar que os sedimentos são mais ricos em nutrientes que o solo de origem (figura 6), isto se deveu à seletividade de arraste superficial da erosão hídrica, que transporta a 
fração mais rica de nutrientes do solo, o que está de acordo com Silva et al. (2005).

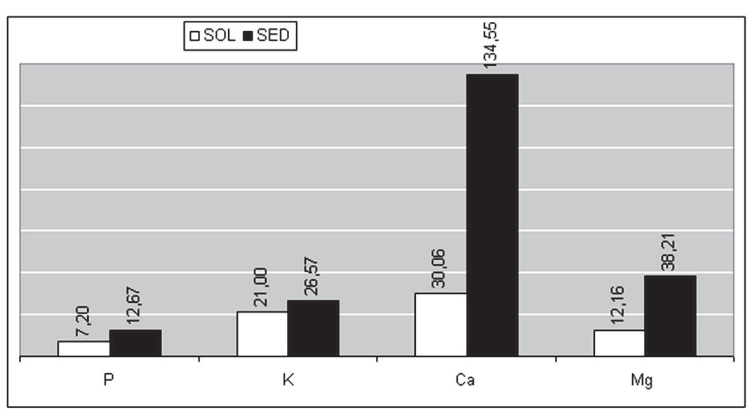

FIGURA 5 - Concentração média dos valores de nutrientes $\left(\mathrm{mg} \mathrm{dm}^{-3}\right)$ do solo (SOL) e dos sedimentos (SED). Fonte: Os autores.

Para transformar os valores de concentrações da análise de $\mathrm{mg} \mathrm{dm}^{-3}$ para $\mathrm{kg} \mathrm{ha}^{-1}$ (tabela 2), considerou a profundidade de 0,2 $\mathrm{m}$ de solo e multiplicou os valores pelo fator de conversão 2 (dois).

As perdas de nutrientes nos sedimentos $\left(\mathrm{kg} \mathrm{ha}^{-1}\right)$ para cada elemento foram calculadas a partir da fórmula:

\section{$\mathbf{P N}=\sum \mathbf{x} /$ PTS}

$\mathrm{PN}=$ perda de nutriente, em $\mathrm{kg} \mathrm{ha} \mathrm{a}^{-1}$;

$\sum \mathrm{x}=$ somatório da concentração do nutriente em cada análise do sedimento, em $\mathrm{kg} \mathrm{ha}^{-1}$; e

$\mathrm{PTS}=$ perda total de solo, em $\mathrm{kg} \mathrm{ha}^{-1}$.

\begin{tabular}{lrrrr}
\hline & \multicolumn{1}{c}{$\mathrm{P}$} & \multicolumn{1}{c}{$\mathrm{K}$} \\
$\mathrm{Kg} \mathrm{ha}^{-1}$ & $\mathrm{Ca}^{+2}$ & $\mathrm{Mg}^{+2}$ \\
\cline { 2 - 5 } 1 SOL & 0,4 & 40,0 & 40,08 & 24,32 \\
2 SOL & 28,4 & 44,0 & 80,16 & 24,32 \\
\hline 1 SED & 0,4 & 46,0 & 240,46 & 24,32 \\
2 SED & 21,4 & 30,0 & 120,24 & 24,32 \\
3 SED & 21,2 & 38,0 & 160,32 & 24,32 \\
4 SED & 18,8 & 38,0 & 120,24 & 48,62 \\
5 SED & 101,8 & 54,0 & 360,70 & 145,88 \\
6 SED & 6,0 & 62,0 & 400,78 & 121,56 \\
7 SED & 7,8 & 104,0 & 480,94 & 145,88
\end{tabular}

O P foi o elemento que teve menor perda $0,63 \mathrm{~kg} \mathrm{ha}^{-1}$. O que pode ser explicado pelo fato deste elemento ser pouco móvel, por apresentar baixa concentração no solo (figura 6) e pelas baixas perdas de sedimentos, sendo que este elemento se encontra fortemente adsorvido as partículas do solo e, portanto, é perdido juntamente com a fração física do solo, concordando com Oliveira (2007).

Para o $\mathrm{K}$ a perda foi de $1,43 \mathrm{~kg} \mathrm{ha}^{-1}$. Sua concentração (figura 5) foi maior que a do $\mathrm{P}$, assim como as perdas, as quais foram inferiores as de $\mathrm{Ca}$ e $\mathrm{Mg}$. Isto se deveu à menor concentração de $\mathrm{K}$ e por ser ele um elemento mais solúvel, que apresenta perdas significativas pela água da enxurrada, corroborando Oliveira (2007).

Nos sedimentos as maiores concentrações foram as de Ca seguido de $\mathrm{Mg}$ (figura 5), assim como as perdas 7,25 e 2,06 $\mathrm{kg} \mathrm{ha}^{-1}$. Isto se deveu à quantidade aplicada de calcário 1,11 t ha ${ }^{-1}$ e pela forma superficial de aplicação, o que elevou sua concentração no solo, além do fato desses elementos, assim como o $\mathrm{P}$, serem perdidos principalmente agregados aos sedimentos, via escoamento superficial.

$\mathrm{Na}$ (tabela 1), as tendências de perdas de nutrientes em ordem decrescente se mostraram da seguinte forma: $\mathrm{Ca}>\mathrm{K}>\mathrm{Mg}>\mathrm{P}$ nas primeiras três análises, concordando com Silva et al. (2005) e Wichert (2005); já na quarta, sexta e sétima análises, apresentaram-se assim: $\mathrm{Ca}>\mathrm{Mg}>\mathrm{K}>\mathrm{P}$, concordando com Oliveira (2007), e de forma não comum na quinta análise $\mathrm{Ca}>\mathrm{Mg}>\mathrm{P}>\mathrm{K}$, não se chegando a uma conclusão sobre esse fato.

As perdas de MO foram irregulares entre as coletas do sedimento, mas a média apresentou os mesmos valores do solo (figura 7), o que está de acordo com Wichert (2005).

De forma geral os sedimentos apresentaram maiores valores do que o solo (figura 6). O pH e a CTC no sedimento apresentaram os valores de 5,37 e 1,12; respectivamente e no solo original estes valores foram 4,46 e 0,63; respectivamente, concordando com Wichert (2005). O pH 
apresentou valores crescentes, o que pode ser explicado pelas perdas, também crescentes dos elementos $\mathrm{Ca}$ e $\mathrm{Mg}$, do início para o fim do estudo (tabela 1).

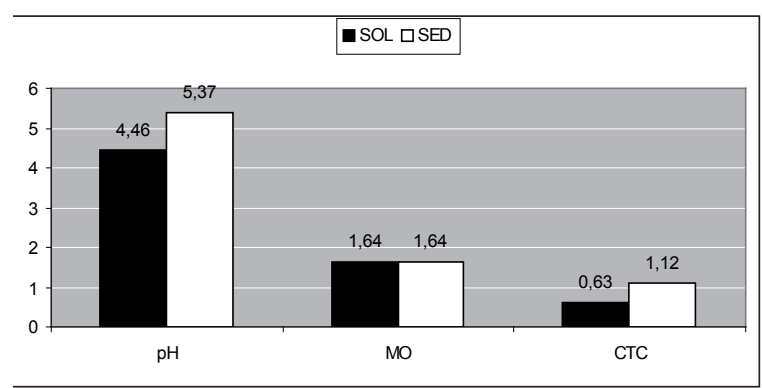

FIGURA 6 - Concentração média dos valores de $\mathrm{pH}\left(\mathrm{H}_{2} \mathrm{O}\right), \mathrm{MO}\left(\mathrm{dag} \mathrm{kg}^{-1}\right)$ e CTC $\left(\mathrm{cmol}_{\mathrm{c}} \mathrm{dm}^{-3}\right)$ no solo (SOL) e no sedimento (SED).Fonte: Os autores.

\section{CONCLUSÕES}

O solo apresentou baixa perda total de nutrientes por erosão hídrica em cultivo de eucalipto sob chuva natural, para o tempo de estudo de quatro meses.

$\mathrm{O} \mathrm{Ca}$ foi o elemento que mais se perdeu por escoamento superficial, seguido de $\mathrm{Mg}, \mathrm{K}$ $\mathrm{e}, \mathrm{o} \mathrm{P}$ foi o elemento que teve a menor perda.

A MO apresentou iguais concentrações tanto para o solo de origem quanto para os sedimentos.

Os sedimentos apresentaram maiores valores de $\mathrm{pH}, \mathrm{CTC}$ e nutrientes que o solo original.

\section{REFERÊNCIAS BIBLIOGRÁFICAS}

BAHIA, V. G. et al. Fundamentos de erosão do solo (tipos, formas, mecanismos, fatores determinantes e controle). Informe Agropecuário. Belo Horizonte, v. 16, n.176, p. 25-31, 1992.

BERTOL, I.; et al. Perdas de fósforo e potássio por erosão hídrica em um inceptisol sob chuva natural. Revista Brasileira de Ciência do Solo, Campinas, v. 28, p. 485-494, 2004a.

BERTOL, I.; et al. Erosão hídrica em um nitossolo háplico submetido a diferentes sistemas de manejo sob chuva simulada. II - Perdas de nutrientes e carbono orgânico. Revista Brasileira de Ciência do Solo, Campinas, v. 28, p. 1045-1054, 2004 b.

CASSOL, E.A.; REICHERT, J.M. Pesquisa em erosão do solo no Brasil. P.399-420. in: ARAÚJO, Q.R. (organizador). 500 anos de usos do salo no Brasil. Ilhéus - BA: editora UESC, 605p. 2002.

CAVICHIOLO; S. R. Perdas de solo e nutrientes por erosão hídrica em diferentes métodos de preparo de solo em plantio de Pinus taeda. Curitiba 2005. 152 f. Tese de Doutorado. UFP.

CHAVES, H.M.L.; ORLOWSKI, E.; ROLOFF, G. Previsão da infiltração sob condições dinâmicas de selamento superficial. Revista Brasileira de Ciência do solo, Campinas, v.17, n.2, p.141-147, 1993.

COGO, N.P.; MOLDENHAUER, W.C.; FOSTER, G.R. Redução de Perdas de solo de Conservação Tillage Practices1. Sociedade de Ciências da América, cap. 48, p.368-373, 1984.

CORRÊA, A. Prejuízos com as perdas de solo nas áreas agrícolas. Disponível em $<\mathrm{http}$ ://www. cnps.embrapa.br/search/planets/coluna14.html > Acesso em: 27 out. 2009.

GONÇAVES, J. L. M. et al. Manejo de resíduos vegetais e preparo do solo. Conservação e cultivo de solos para plantações florestais. Instituto de Pesquisa e Estudos Florestais -IPEF. Cap. 3, p.133-204, Piracicaba, São Paulo, 2002.

GUADAGNIN, J. C.; et al. Perdas de solo, água e nitrogênio por erosão hídrica em diferentes sistemas de manejo. Revista Brasileira de Ciência do Solo, Campinas, v. 29, p. 277-286, 
2005.

HERNANI, L.C.;et al. Perdas por erosão e rendimento de soja e de trigo em diferentes sistemas de preparo de Latossolo Roxo de Dourados - MS. Revista Brasileira de ciência do solo, Campinas, v.21, n.4, p.667-76, 1997

LOPES, A. S.; GUILHERME, L. R. G.; Interpretações de análise de solo, conceitos e aplicações. Boletim técnico número 2. Associação Nacional para Difusão de adubos, 2004.

OLIVEIRA, J. R.; Perdas de solo, água e nutrientes em um argissolo vermelho-amarelo sob diferentes padrões de chuva simulada. UFRRJ, Seropédica, 2007.

PIRES, L. S.; et al. Erosão hídrica pós-plantio em florestas de eucalipto na região centro-leste de Minas Gerais. Pesquisa Agropecuária Brasileira, Brasília, v. 41, n. 4, p. 687-695, 2006.

PIRES, L. S.; Sistema de manejo de eucalipto e erosão hídrica em Latossolo Vermelho-Amarelo muito argiloso na região de Belo Oriente (MG). 2004. 84p. Dissertação (Mestrado) - Universidade
Federal de Lavras, Lavras.

SILVA, A. M.; et al. Perdas de solo, água, nutrientes e carbono orgânico em combissolo e latossolo sob chuva natural. Pesquisa Agropecuária Brasileira, Brasília, v. 40, n. 12, p. 1223-1230, 2005.

SILVA, J. V.; et al. Perdas de solo e água por erosão hídrica em floresta equiânea em um Latossolo Vermelho-Amarelo. Revista Brasileira de Ciências Agrárias, Pernambuco. - NO PRELO.

VEIGA, M.; etal. Erodibilidade em entressulcos de solos do Rio Grande do Sul. Revista Brasileira de Ciência do Solo, Campinas, v. 17, n. 1, p. 121-128, 1993.

WICHERT, M. C. P.; Erosão hídrica e desenvolvimento inicial do Eucalyptus grandis em um argissolo vermelhoamarelo submetido a diferentes métodos de preparo de solo no vale do Paraíba SP. Dissertação (Mestrado em Recursos Florestais) - ESALQ, Piracicaba, 2005. 